\title{
Level of Knowledge and Behavior of Family Health Personnel Workers in Izmir about Early Diagnosis for Breast and Cervix Cancer
}

\author{
Gokben Yasli ${ }^{1}$, Ebru Turhan ${ }^{2 *}$, Sultan Eser $^{3}$, Mustafa Tozun ${ }^{4}$, Murat Oguz $^{3}$, \\ Fatma Alpay ${ }^{3}$
}

\begin{abstract}
Purpose: The present study was carried out to measure knowledge level and behavior of family health personnel (FHP) in Izmir on early diagnosis of breast and cervical cancers. Materials and Methods: The study population of this cross-sectional study was not selected. A questionnaire was applied to all FHP to measure knowledge level and behavior about cancer. The participation rate was $88 \%$. Breast examination, mammography analysis, Papanicolaou smear applications were determined as dependent variables, and knowledge level about breast and cervical cancer, age, professional time as FHP as independent variables. Data were evaluated using definitive

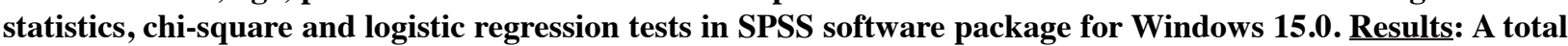
of 970 family health personnel participated in the research. The age range was $20-45$ years $(82.4 \%)$. Mean age was 37.9 7.4. Response rate was $87.3 \%$. Of the participants, $88.4 \%$ performed breast self-examination. Rate of performing mammography at least once was $24.1 \%$. Rate of performing Pap-smear examination at least once was $61.0 \%$. In logistic regression analyses, it was determined that people with knowledge on breast and cervical cancer were those performing breast self-examination, mammography and Pap-smear examinations $(\mathbf{p}<0.05$. Conclusions: It is essential that the knowledge, behavior and manners of health providers on early diagnosis for cancer increases awareness in the general population and provides information on execution ofthe most effective methods for generating a healthy society.
\end{abstract}

Keywords: Breast cancer - cervical cancer - cancer screening - family health personnel - Izmir, Turkey

Asian Pac J Cancer Prev, 16 (6), 2501-2505

\section{Introduction}

Cancer is one of the most significant problems related to public health today. It is in the second place among the death causes in our country. Cancer has become the second most common cause of death in especially developing countries as well as in the developed countries and moved ahead of infectious diseases (respiratory tract, HIV/AIDS, diarrhea, tuberculosis etc.) (Anderson et al., 2007). By the early diagnosis of breast and cervix cancers that could be prevented after scanning a decrease rate of $85 \%$ in mortality is provided (ACS, 2008).

Breast cancer is the most common cancer type among women not only in developing but also in developed countries. Furthermore, breast cancer is one of the most important cause of death for women (Erefe et al., 2006). According to the data of Globokan 2002, breast cancer is among the most common and most death-causing cancers for women in our country (Parkin et al., 2005). It is recommended for any woman to perform breast self-examination and clinical examinations after age of 20 regularly and the first mammography at the age of 40 and control mammography between the age of 50 and 69 regularly (Anderson et al., 2003; Smith et al., 2006; Modjtabai et al) With mammography, the breast cancer is determined in the rate of $80-90 \%$ without any symptoms and treated efficiently and the live chance of individuals increases (ACS, 2008). BSE is a cheap and non-risky method. American Cancer Society offers to give information to women about benefits and limits of BSE. Women find out their breast structure with regular breast examinations and become aware about the differences easily (Gray et al., 1990; Epstein et al., 2001; Anderson et al., 2003).

Cervix cancer is in the second rank after breast cancer among the women cancers in the world (Guner et al., 2007). In developing countries, cervical cancer is a significant cause of death in reproduction period of women (Ayhan et al., 2007). Despite of the fact that epidemiological data, related to our country, is limited, 
according to 2003 data of Ministry of Health, cervix cancer is in rank 9 in Turkey and incidence is 2,20 in 100,000 . In a new study in 8 cities, deemed as representing Turkey, the incidence of cervix cancer is 4,76 in 100,000. Cervix cancer is in higher rate in developing countries for reasons such as insufficient routine scanning programs, low social-economic status, bad hygiene, early coitus, multi-sexual partners. So, the disease is diagnosed in advanced stage and the treatability of the disease decrease in developing countries (Dede et al., 1996). For the early diagnosis of the cervix cancer, HPV or Pap smear scanning is recommended once in 5 years between the ages of 30 and 65. World Health Organization says that Pap smear test can reduce the invasive cancer risk in the rate of $65 \%$ (WHO, 1986).

Knowledge level and behaviors of the health providers, related to the breast and cervix cancer diagnosed early, are important from the point of being a model for the society. This study was performed to measure knowledge level and manners of family health personnel

\section{Materials and Methods}

The cross-sectional type study was carried out between the dates of February and March 2012. The population of the research constitutes totally 1106 personnel of family health (FHP) in Izmir. We tried to reach all the population that the sample was not selected. Questionnaire was applied to family health personnel to measure the knowledge level and behaviors about cancer. 970 personnel of family health participated in this questionnaire (FHP:1106, participation rate: $88 \%$ ). Breast Self-Examination, mammography analysis, pap smear applications are determined as dependent variable and knowledge level about breast and cervix cancer, age, professional time of FHP are determined as independent variable. Data is evaluated in SPSS for Windows 15.0 Statistical Packet Program and defining statistics, chisquare test and logistic regression tests are applied in analysis.

\section{Results}

970 personnel of family health participated in the research. The age range is $20-45(82.4 \%, \mathrm{n}=790)$. Age average is $37.9 \pm 7.4$. They are midwife and nurse in institutions in the rate of $87.3 \%(n=848)$. The professional time of $39,1 \%(n=380)$ is $10-20$ years.

The $88.4 \%(n=791)$ of the participants perform breast self-examination. The rate of those going to doctor for breast examination is $16.8 \%(n=152)$. The rate of those performing mammography application at least once is $24.1 \%(n=219)$. The women in age of 45 and over performed more mammography tests than the other age groups $(36.8 \%, \mathrm{n}=39, \mathrm{p}=0.000)$. The rate of those performing Pap smear application at least once is $61.0 \%$ $(n=564)$. The women in age of 45 and over performed more pap smear tests than the other age groups $(75.9 \%$, $\mathrm{n}=82, \mathrm{p}=0.000)$.

The most correct replies given by FHPs for the questions related to early diagnosis methods are those relating to the application time of BSE before and after menopause (46.4\% and 67.4\%) and the least correct replies are those relating to the application time of Pap smear and beginning time of BSE (27.3\% and 10.9\%).

The risk factor of "non-birthing situation" is the most known of breast cancer risk factors $(85.5 \%)$ and the second rank is risk factor of "breast cancer on the close relatives" $(75.5 \%)$. The risk factor of "Every woman,

Table 1. The Percentage Distribution of the Replies for the Questions Related to the Early Diagnosis Methods of Family Health Personnel

$\mathrm{n}(\%)$

What is the most suitable age for participating in Breast SelfExamination (BSE)?

\begin{tabular}{lr}
15 & $143(15.7)$ \\
20 & $248(27.3)$ \\
30 & $96(10.6)$ \\
After the first menstruation & $422(46.4)$ \\
Which periods should be BSE applied? & $143(15.7)$ \\
Any day within menstruation & $248(27.3)$ \\
1-4th days of menstruation & \\
$5-7$ days later from the beginning of menstruation $96(10.6)$ \\
7-10th days from the beginning of menstruation & $422(46.4)$ \\
2-4 days later from the end of menstruation & \\
When should BSE applied after menopause? & $8(0.9)$ \\
Only when the estrogen is taken & $195(21.7)$ \\
Any day, once in a month & $606(67.4)$ \\
Specific day in every month & $90(10.0)$ \\
Same day every 6 months & \\
Which frequency should the pap smear test applied for the age \\
30-65? \\
Once in 6 months & $172(18.5)$ \\
Once in a year & $639(68.8)$ \\
Once in 5 years & $101(10.9)$ \\
In case of complaint & $4(0.4)$ \\
In case of doctor demand & $5(0.5)$ \\
\hline
\end{tabular}

Table 2. The Percentage Distribution of the Replies of Family Health Personnel for the Questions Related to the Risk Factors

\begin{tabular}{|c|c|}
\hline Risk factors for breast cancer & $\mathrm{n}(\%)$ \\
\hline Aging is risk factor for breast cancer & $329(40.6)$ \\
\hline \multicolumn{2}{|c|}{$\begin{array}{l}\text { The non-birthing situation is risk factor for breast cancer } \\
759(85\end{array}$} \\
\hline $\begin{array}{l}\text { The first birthing situation over the age of } 30 \text { is ri } \\
\text { breast cancer }\end{array}$ & $\begin{array}{l}\text { sk factor for } \\
567(66.9)\end{array}$ \\
\hline $\begin{array}{l}\text { Late menopause (over age 50) is not risk factor } \mathrm{f} \\
\text { cancer }\end{array}$ & $\begin{array}{l}\text { or breast } \\
494(58.9)\end{array}$ \\
\hline $\begin{array}{l}\text { The first menstruation in early age is risk factor } \mathrm{f} \\
\text { cancer }\end{array}$ & $\begin{array}{l}\text { for breast } \\
346(41.6)\end{array}$ \\
\hline $\begin{array}{l}\text { Breast cancer appearing on close relatives (moth } \\
\text { sister, aunt) is not risk factor for breast cancer }\end{array}$ & $\begin{array}{l}\text { er, daughter, } \\
648(75.5)\end{array}$ \\
\hline \multicolumn{2}{|l|}{ Risk factors for cervix cancer } \\
\hline \multicolumn{2}{|c|}{$\begin{array}{l}\text { Every woman, being active sexually, should apply pap smear } \\
\text { test } \\
802(90.7)\end{array}$} \\
\hline \multicolumn{2}{|c|}{ The bleeding in intervals of cycle may be the early symptoms } \\
\hline for cervix cancer. & $621(72.5)$ \\
\hline Smoking is risk factor for cervix cancer & $684(78.5)$ \\
\hline Cervix cancer is not associated with HPV & $596(72.0)$ \\
\hline Cervix cancer starts to appear in the age of $30 \mathrm{~s}$. & $382(45.7)$ \\
\hline Cancer story in the family is not risk factor for ce & $\begin{array}{r}\text { ervix cancer } \\
690(81.2)\end{array}$ \\
\hline HPV is a sexually transmitted virus. & $727(84.9)$ \\
\hline
\end{tabular}


Knowledge and Screening Behavior of Family Health Personnel Workers in Izmir about Breast and Cervix Cancer

being active sexually, should applied pap smear test" is the most known of cervix cancer risk factors $(97.0 \%)$ and the second rank is risk factor of "HPV is a sexually transmitted virus" (81.2\%)

As shown in table 3, the BSE frequency of the women under the age of 25 from the participants is more and meaningful than the other age groups $(95.1 \%$ and $\mathrm{p}=0.041)$.

The BSE frequency of the women whose professional period is 10 year or under is more and meaningful than the other age groups $(91.6 \%$ and $\mathrm{p}=0.023)$.

The BSE frequency of the women whose knowledge is sufficient is more and meaningful than the other women whose knowledge is insufficient or in medium level $(\mathrm{p}=0.044)$.

When the mammography application of women in table 3 is reviewed, the frequency of mammography application is increasing by the age $(p=0.000)$. The frequency of mammography application is increasing and meaningful by the professional period is increasing $(p=0.000)$. The $31.5 \%$ of the women, whose knowledge about breast cancer is sufficient, have applied more mammography tests than the women, whose knowledge is insufficient or in medium level (Respectively, 31.5\%, $20.9 \%$ and $\mathrm{p}=0.001$ ).

When the smear test situation in table 3 is reviewed, the frequency of smear test application is increasing by the age $(p=0.000)$. Furthermore, the frequency of mammography application is increasing by the professional period is increasing $(\mathrm{p}=0.000)$. The women, whose knowledge about cervix cancer is sufficient, have applied more smear test application than the women, whose knowledge is insufficient or in medium level (Respectively, 69.7\% and $59.1 \%, \mathrm{p}=0.001)$.

The variants deemed as meaningful in the univariant analysis are taken to the logistic regression analysis. These are considered as reference: Being over 45 , less professional period than 10 years, insufficient knowledge about breast cancer and insufficient knowledge about cervix cancer.

According to the logistic regression analysis, the professional period of 10-20 years and sufficient knowledge of prevention for breast cancer affects BSE application. Being professional for 10-20 years increases

Table 3. Application of Early Diagnosis Methods by Family Health Personnel According to Some Features

\begin{tabular}{|c|c|c|c|c|c|c|c|c|c|}
\hline & \multicolumn{3}{|c|}{$\begin{array}{c}\text { BSE } \\
\text { application }\end{array}$} & \multicolumn{3}{|c|}{$\begin{array}{c}\text { Mammography } \\
\text { application }\end{array}$} & \multicolumn{3}{|c|}{$\begin{array}{l}\text { Smear test } \\
\text { application }\end{array}$} \\
\hline & $\mathrm{E}$ & $\mathrm{H}$ & $\mathrm{p}$ & $\mathrm{E}$ & $\mathrm{H}$ & $\mathrm{p}$ & $\mathrm{E}$ & $\mathrm{H}$ & $\mathrm{p}$ \\
\hline \multicolumn{10}{|l|}{ Age } \\
\hline Under 25 & 95.1 & 4.9 & & 4.9 & 95.1 & & 24.4 & 75.6 & \\
\hline Age $25-45$ & 87.1 & 12.9 & 0.041 & 17.7 & 82.3 & $<0.001$ & 60.7 & 39.3 & $<0.001$ \\
\hline Over 45 & 94.2 & 5.8 & & 73.8 & 90.2 & & 75.9 & 24.1 & \\
\hline \multicolumn{10}{|l|}{ Professional Period } \\
\hline Under 10 & 91.6 & 8.4 & & 6.5 & 93.5 & & 43.6 & 56.4 & \\
\hline $10-20$ years & 84.8 & 15.2 & 0.023 & 9.4 & 90.6 & $<0.001$ & 60.7 & 39.3 & $<0.001$ \\
\hline 20 yearsandover & 90.1 & 9.9 & & 52 & 48 & & 72.4 & 27.6 & \\
\hline \multicolumn{10}{|c|}{ Having knowledge of prevention for breast cancer } \\
\hline Sufficient & 91.7 & 8.3 & 0.044 & 31.5 & 68.5 & 0.001 & & & \\
\hline İnsufficient or in medium level & 87 & 13 & & 20.9 & 79.1 & & & & \\
\hline \multicolumn{10}{|c|}{ Having knowledge of prevention for cervix cancer } \\
\hline Sufficient & & & & & & & 69.7 & 30.3 & 0.009 \\
\hline İnsufficient or in medium level & & & & & & & 59.1 & 40.9 & \\
\hline
\end{tabular}

*Percentage line

Table 4. BSE, Mammography and Smear Test Applications According to Logistic Regression Analysis*

\begin{tabular}{llrrrr}
\hline & & $\beta$ & $\mathrm{p}$ & OR & $\% 95$ CI \\
\hline BSE application & Under 25 years & 0.104 & 0.906 & 1.110 & $0.196-6.295$ \\
& Age 25-45 years & 0.816 & 0.076 & 2.262 & $0.917-5.579$ \\
Professional Period & 10-20 years & 0.671 & 0.019 & 1.957 & $1.115-3.436$ \\
& 20 years and over & 0.182 & 0.556 & 1.199 & $0.655-2.197$ \\
Having knowledge of prevention for breast cancer & Sufficient & 0.662 & 0.028 & 1.939 & $1.076-3.495$ \\
Mammography Application & Under 25 years & 2.384 & 0.003 & 10.850 & 2.22053 .032 \\
& Age 25-45 years & 1.634 & 0.000 & 5.124 & $3.079-8.528$ \\
Professional Period & 10-20 years & -0.303 & 0.373 & 0.739 & $0.379-1.438$ \\
& 20 years and over & -2.185 & 0.000 & 0.112 & $0.061-0.208$ \\
Having knowledge of prevention for breast cancer & Sufficient & 0.524 & 0,022 & 1.688 & $1.080-2.639$ \\
Smear test application & Under 25 years & 1.449 & 0.002 & 4.260 & 1.71510 .582 \\
& Age 25-45 years & 0.307 & 0.239 & 1.359 & $0.815-2.265$ \\
Professional Period & 10-20 years & -0.496 & 0.007 & 0.609 & $0.425-0.871$ \\
& 20 years and over & -0.953 & 0.000 & 0.386 & $0.259-0.574$ \\
Having knowledge of prevention for cervix cancer & Sufficient & 0.530 & 0.013 & 1.699 & $1.116-2.587$ \\
\hline
\end{tabular}

*These are considered as reference: Being over 45, less professional period than 10 years, insufficient knowledge about breast cancer and insufficient knowledge about cervix cancer 
BSE application in 1.9 times than the other age groups. The possibility of BSE application of the women, whose knowledge about breast cancer is sufficient, is more than possibility of the women, whose knowledge is insufficient, in 1.9 times. The reliability interval is meaningful because it does not consist of 1 .

Age, professional period of 20 years and over, sufficient knowledge of breast cancer affects mammography application in a significant level according to logistic regression analysis. The possibility of mammography application of the women, whose knowledge about breast cancer is sufficient, is more than possibility of the women, whose knowledge is insufficient, in 1.7 times. The reliability interval is meaningful because it does not consist of 1 .

Being under 25, professional period and sufficient knowledge of cervix cancer affects Pap smear test application in a significant level according to logistic regression analysis. The possibility of Pap smear test application of the women, whose knowledge about cervix cancer is sufficient, is more than possibility of the women, whose knowledge is insufficient, in 1.7 times. The reliability interval is meaningful because it does not consist of 1 .

\section{Discussion}

A total of 970 personnel of family health participated in the research. The age range is $20-45(82.4 \%, \mathrm{n}=790)$. Age average is $37.9 \pm 7.4$. They are midwife and nurse in institutions in the rate of $87.3 \%(n=848)$. The professional time of $39,1 \%(n=380)$ is $10-20$ years.

The $88.4 \%(n=791)$ of the participants perform breast self-examination. The rate of those going to doctor for breast examination is $16.8 \%(n=152)$. The rate of those performing mammography application at least once is $24.1 \%(n=219)$. The women in age of 45 and over performed more mammography tests than the other age groups $(36.8 \%, \mathrm{n}=39, \mathrm{p}=0.000)$. The rate of those performing Pap smear application at least once is $61.0 \%$ $(n=564)$. The women in age of 45 and over performed more pap smear tests than the other age groups $(75.9 \%$, $\mathrm{n}=82, \mathrm{p}=0.000)$.

The most correct replies given by FHPs for the questions related to early diagnosis methods are those relating to the application time of BSE before and after menopause (46.4\% and 67.4\%) and the least correct replies are those relating to the application time of Pap smear and beginning time of BSE (27.3\% and $10.9 \%)$.

The risk factor of "non-birthing situation" is the most known of breast cancer risk factors $(85.5 \%)$ and the second rank is risk factor of "breast cancer on the close relatives" $(75.5 \%)$. The risk factor of "Every woman, being active sexually, should applied pap smear test" is the most known of cervix cancer risk factors (97.0\%) and the second rank is risk factor of "HPV is a sexually transmitted virus" $(81.2 \%)$

As shown in table 3 , the BSE frequency of the women under the age of 25 from the participants is more and meaningful than the other age groups $(95.1 \%$ and $\mathrm{p}=0.041)$.
The BSE frequency of the women whose professional period is 10 year or under is more and meaningful than the other age groups $(91.6 \%$ and $\mathrm{p}=0.023)$.

The BSE frequency of the women whose knowledge is sufficient is more and meaningful than the other women whose knowledge is insufficient or in medium level $(\mathrm{p}=0.044)$.

When the mammography application of women in Table 3 is reviewed, the frequency of mammography application is increasing by the age $(p=0.000)$. The frequency of mammography application is increasing and meaningful by the professional period is increasing $(p=0.000)$. The $31.5 \%$ of the women, whose knowledge about breast cancer is sufficient, have applied more mammography tests than the women, whose knowledge is insufficient or in medium level (respectively, 31.5\%, $20.9 \%$ and $\mathrm{p}=0.001$ ).

When the smear test situation in table 3 is reviewed, the frequency of smear test application is increasing by the age $(p=0.000)$. Furthermore, the frequency of mammography application is increasing by the professional period is increasing $(\mathrm{p}=0.000)$. The women, whose knowledge about cervix cancer is sufficient, have applied more smear test application than the women, whose knowledge is insufficient or in medium level (respectively, 69.7\% and $59.1 \%, \mathrm{p}=0.001)$.

The variants deemed as meaningful in the univariant analysis are taken to the logistic regression analysis. These are considered as reference: Being over 45 , less professional period than 10 years, insufficient knowledge about breast cancer and insufficient knowledge about cervix cancer.

According to the logistic regression analysis, the professional period of 10-20 years and sufficient knowledge of prevention for breast cancer affects BSE application. Being professional for 10-20 years increases BSE application in 1.9 times than the other age groups. The possibility of BSE application of the women, whose knowledge about breast cancer is sufficient, is more than possibility of the women, whose knowledge is insufficient, in 1.9 times. The reliability interval is meaningful because it does not consist of 1 .

Age, professional period of 20 years and over, sufficient knowledge of breast cancer affects mammography application in a significant level according to logistic regression analysis. The possibility of mammography application of the women, whose knowledge about breast cancer is sufficient, is more than possibility of the women, whose knowledge is insufficient, in 1.7 times. The reliability interval is meaningful because it does not consist of 1 .

Being under 25, professional period and sufficient knowledge of cervix cancer affects Pap smear test application in a significant level according to logistic regression analysis. The possibility of Pap smear test application of the women, whose knowledge about cervix cancer is sufficient, is more than possibility of the women, whose knowledge is insufficient, in 1.7 times. The reliability interval is meaningful because it does not consist of 1 .

In conclusion, in the formation of a healthy society, it's 
important that especially the family health personnel to adopt the knowledge, attitudes and behaviours concerning methods for early diagnosis of cancer. In this way, the awareness for early diagnosis of cancer in a normal population may be increased and the implementation of early diagnosis methods can be achieved. The successful implementation of a struggle with cancer can only be achieved by a serious, planned and organized study.

\section{References}

Açıkgöz A, Ellidokuz H (2011). Women's knowledge and attitude about cancer and the behaviour for early diagnosis procedures, Dokuz Eylul University Faculty of Medicine, 25, 145-54.

Akyuz A, Guvenc G,Yavan T, et al (2006). Evaluation of the pap smear test status of women and of the factors affecting this status. Gulhane Medical Journal, 48, 25-29.

American Cancer Society (2008).http://www.cancer.org/ downloads/STT/cafffinalsecured.pdf

American Cancer Society (2008).http://www.cancer.org/ downloads/STT/cafffinalsecured.pdf

Anderson B, Brown S, Lim S, et al (2003), Early detection of breast cancer in countries with limited resources. Breast $J$, 9, 51-9.

Anderson GF (2007). Expanding priorities confronting chronic disease in countries with low income. $N$ Engl J Med, 356, 209-11.

Aslan A, Temiz M, Yigit Y, et al (2007). The knowledge attitude and behaviorus of nursey students about breast cancer, Prevent Med Bull, 6, 1938.

Ayhan A (2007). Cervical neoplasia. gomel of gynecology, nobel medical bookstores. Nobel Printing, Istanbul.

Bankaoglu OA, Ekerbicer H C, Hudayioglu M R, et al (2009). The status of breast self examination and having mammography as well as affecting factors in a group of women in Kahramanmaras. Community Med Bull, 28, 14-9

Behbakht K, Lynch A, Teal S, et al (2004). Social and cultural barriers to papanicolaou test screening in an urban population. Am College Obstets Gynecologists, 1355-61.

Champion VL(1995). Development of a benefits and barriers scale for mammography utilization. Cancer Nursing, 18, 53-9.

Coe K, Harmon MP, Castro EG, et al (1994). Breast self examination: Knowledge and practices of Hispanic women in two South western Metropolitan Areas. J Community Health, 19, 433-48.

Cadir G, Eksen M, Butuner E, et al (2004). Determining knowledge level and aplication self breast check and breast cancer of women in Mugla country, Yesilyurt health center areas, Int J Human Sci, 1303-5134

Dede M, Yenen M, Keskin U, et al (1996). Cervical cancer and laparoscopy. basic gynecology and obstetrics. Sun Medical Publishing House, Istanbul.

Diliuz Dogan B, Ergin F, Hekim B, et al (2003). Women aged 30 to 69 living in the city of Aydin's breast and cervical cancer early diagnosis and screening programs about the knowledge, attitude and behavior, 16. Public Health Congress.

Doganer Y, Aydogan U, Kilbas Z, et al (2014). Predictors affecting breast self-examination practice among Turkish women, Asian Pac J Cancer Prev, 15, 9021-5

Duran E, Koc S, Korkmaz M, et al (2014). Turkish social attitudes towards to cancer prevention: a Health Belief Model Study, Asian Pac J Cancer Prev, 15, 7951-4

Dundar P.E, Ozmen D, Ozturk B, et al (2006). The knowledge and attitudes of breast self-examination and mammography in a group of women in a rural area in western Turkey. $B M C$ Cancer, 6, 43-51.

Epstein SS, Bertell R, Seaman B, et al (2001). Dangers and unreliability of mammography: breast examination is a safe, effective, and practical alternative, Int J HealthServ, 31, 605-15.

Erefe I, Early Diagnosis, Public Health Nursing Handbook, Vehbi Koc Publications, 14, 60-62.

Facione NC, Giancarlo C, Chan L, et al (2000). Perceived risk and help seeking behavior for breast cancer. Cancer Nursing, 23, 256-264

Fung S (1998). Factors associated with breast self-examination behaviour among Chinese women in Hong Kong. Patient Educand Couns, 333, 33-243.

Göcgeldi E, Acikel C, Hasde M, et al (2008). Investigation of attitudes and behaviors of a group of women who reside at in Ankara Golbasi on self-breast examination, Firat Medical, 13, 261-5.

Gray ME (1990). Factors related to practice of breast selfexamination in rural women. Cancer Nurs, 13, 100-107.

Guner H (2007). Epidemiology of cervical cancer and the role of human papilloma virus. J Turk Soc Obstet Gynecol, 4, 11-19.

Jarvandi S, Montazeri A, Harirchi I, et al (2002). Beliefs and behaviours of Iranian teachers toward early detection of breast cancer and breast self-examination, Public Health, 116, 245-9.

Joun HS, Seung-Lee C, Klassen AC, et al (2003). Predictors of regular Pap smears among Korean-American women. Prev Med, 37, 585-592.

Modjtabai A (Editor) (2006).Guidelines for the early detection and screening of breast cancer, WHO. EMRO Technical Publication Series 30.

Onsuz M, Hidiroglu S, Sarioz A, et al (2014). Knowledge, attitudes and behaviors of women over 20 years old on cervix cancer in Istanbul, Turkey. Asian Pac J Cancer Prev, 15, 8801-07

Ozdemir O (2010). Knowledge and practices of nurses working in an education hospital on early diagnosis of breast and cervix cancers, TAF Prev Med Bull, 9, 605-612

Parkin DM, Bray F, Ferlay J, et al (2005). Global Cancer Statistics. 2002 CA Cancer J Clin, 55, 74-108.

Sant M, Francisci S, Capocaccia R, et al (2006). Time trends of breast cancer survival in Europe in relation to incidence and mortality. Int J Cancer. 119, 2417-22.

Smith RA, Cokkinides V, Eyre HJ, et al (2006). American cancer society guidelines for the early detection of cancer, CA Cancer J Clin, 56, 11-25.

Sönmez Y, Nayir T, Köse S, et al (2012). Breast in women 20 years and older and behavior related to early diagnosis of cervical cancer in a health center. Med J Suleyman Demirel University, 19, 124-130.

Senol L V, Balci E, Cetinkaya F, et al (2012).Women's knowledge and behavior on cervical cancer, in Kayseri, Turkey, Turkiye Klinikleri J Med Sci, 32, 694-701

Uncu F (2011). Knowledge, attitude and behavior of midwives and nurses working in primary health services on breast cancer early diagnosis practices. J Breast Health, 7, 167-75

WHO Meeting (1986). Control of cancer of the cervix uteri. Bull WHO, 64, 607- 18. 